\title{
EFFECT OF EUGENOL-BASED ENDODONTIC SEALER ON THE ADHESION OF INTRARADICULAR POSTS CEMENTED AFTER DIFFERENT PERIODS
}

\author{
Larissa Lustosa Lima DIAS ${ }^{1}$, Alessandro Rogério GIOVANI ${ }^{2}$, Yara Teresinha Corrêa SILVA SOUSA ${ }^{3}$, Luiz Pascoal VANSAN 4 , \\ Edson ALFREDO ${ }^{4}$, Manoel Damião SOUSA-NETO ${ }^{5}$, Silvana Maria PAULINO ${ }^{3}$
}

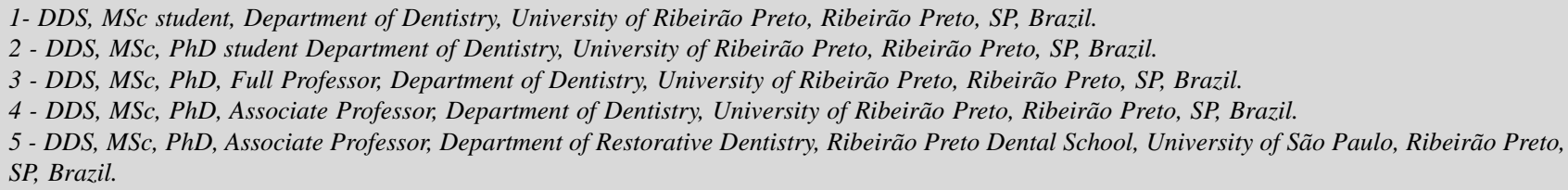

Corresponding address: Silvana Maria Paulino - Rua Florêncio de Abreu, 1201- Ap. 92 Centro - 14015-060 - Ribeirão Preto - SP - Brasil - Phone: +5516-9994-3926 - Fax: +55-16-39311072 - e-mail: silvana.paulino@gmail.com

Received: August 22, 2008 - Modification: February 10, 2009 - Accepted: May 18, 2009

\begin{abstract}
$O$

bjective: This study evaluated in vitro the influence of an eugenol-based sealer (EndoFill) on the retention of stainless steel prefabricated posts cemented with zinc phosphate and resin-based (Panavia F) cements after different periods of root canal obturation, using the pull-out test. Material and methods: Sixty upper canines were decoronated and the roots were embedded in resin blocks. The specimens were distributed into 3 groups, according to the period elapsed between canal obturation and post cementation: Group I - immediately; Group II - $72 \mathrm{~h}$ and Group III - 4 months. The groups were subdivided according to the type of cement used for post cementation: A - zinc phosphate and B - Panavia F. Following the experimental periods, specimens were subjected to pullout test in an Instron machine with application of tensile force at a crosshead speed of $0.5 \mathrm{~mm} / \mathrm{min}$ until post dislodgement. The maximum forces required for post removal were recorded $(\mathrm{kN})$ and means were subjected to statistical analysis by 2-way ANOVA and Tukey-Kramer test $(\alpha=0.001)$ Results: There were statistically significant differences $(p<0.01)$ between the posts cemented with zinc phosphate cement $(0.2112 \mathrm{kN})$ and Panavia $\mathrm{F}(0.0501 \mathrm{kN})$. However, no statistically significant differences $(\mathrm{p}>0.05)$ were found between the three post cementation periods, regardless of the cement. Conclusions: It was concluded that the eugenol-based sealer influenced the tensile strength of the posts cemented with the resin cement, but had no influence on the time waited between root canal obturation and post space preparation/post cementation.
\end{abstract}

Key words: Endodontics. Dentistry. Post. Zinc oxide-eugenol cement.

\section{INTRODUCTION}

Intraradicular posts are recommended in the rehabilitation of endodontically treated teeth where the clinical crown has been partially or totally destroyed and requires prosthetic treatment. Their use promote the union and retention between the prosthetic crown and the remaining radicular structure ${ }^{16,18}$ and also prevent the passage of microorganisms and organic liquids to the interior of the root canals ${ }^{19,28}$. Retention and stability of intraradicular posts in relation to the roots that house them are fundamentally dependent on their anatomic characteristics, post space preparation and the physicochemical properties of the luting agents ${ }^{6}$

Cementation is defined as the use of a modelable substance to seal or cement two parts, keeping them together, promoting retention and sealing of the space between them, minimizing microleakage $e^{4}$. The capacity of different cements to retain posts is related to their mechanical properties, their capacity of interlocking to metal and dentin, and their durability ${ }^{3}$.

Zinc phosphate cement has been widely used in the cementation of intraradicular posts; however, it does not form a chemical union (adhesion) with the dentin and the metal ${ }^{4}$. The resistance of posts cemented with zinc phosphate to removal by traction is related to their mechanical retention to irregularities of the dentin or the metal ${ }^{18}$. According to some authors ${ }^{9,2}$, zinc phosphate cement is friable, which may lead to failures such as post loosening and subsequent root fracture, when subjected to horizontal forces.

With the development of adhesive materials, such as glass ionomer and resin cements, a new perspective has 
arisen in relation to the increase of post retention, due to the adhesion potential of these materials both to the metal alloy and to the dentin ${ }^{18}$.

Resin cements, unfilled resins and adhesive systems have been recommended for the cementation of metal parts due to their good performance in tests evaluating adhesion, resistance to removal by traction and decrease of coronal leakage ${ }^{4,5,22}$. Furthermore, Saupe, et al. ${ }^{21}$ (1996) have reported that resin cements are able to reinforce the weakened root structure, making it more resistant to fracture.

It has been demonstrated that, among other factors, the force required for post removal depends on the type of cement used for post fixation ${ }^{9,17,18}$. Posts cemented with resin agents require greater force for removal when compared to those cemented with zinc phosphate. According to Gomes, et al. ${ }^{12}$ (2006), the adhesion of resin compounds to the root canal and post retention can be affected by the type of endodontic sealer and certain irrigation solutions used in the biomechanical preparation. Many studies have evaluated the effect of endodontic sealers and their compounds in the retention of intraradicular posts, and the results have shown a decrease in the retention of posts cemented fixed with resin cements, in canals obturated with cements containing eugenol ${ }^{2,8,11,12,13,14,25,27}$. Some authors have reported that eugenol interferes in the polymerization of resin compounds, altering different physical and mechanical properties ${ }^{1,10,12,27}$. According to Hagge, et al. ${ }^{14}$ (2002), a longer interval between canal obturation with a zinc oxide and eugenolbased cement and post cementation had a negative effect on retention, probably because of the penetration of eugenol into the dental tubules due to the longer contact time of the endodontic sealer with the root canal walls. Thus, it is possible that the period between root canal obturation with zinc oxide and eugenol-based cement and post space preparation may cause adverse effects in the resin cements used for post cementation, inhibiting its retention ${ }^{27}$.

Considering that zinc oxide and eugenol-based sealers are the most widely used by endodontists worldwide, the purpose of this study was to evaluate in vitro the influence of a zinc oxide and eugenol-based endodontic sealer on the retention of intraradicular posts fixed with resin and zinc phosphate cements after different periods of root canal obturation, using the pull-out test. The null hypothesis was that there is no difference in the retention of posts cemented with different cements in endodontically treated teeth.

\section{MATERIAL AND METHODS}

Sixty non-restored caries-free human maxillary canines with roots of similar shape were selected. All selected teeth had a single canal and straight roots measuring approximately $15 \mathrm{~mm}$. The clinical crowns were sectioned transversally close to the cementoenamel junction leaving a root length of $14 \mathrm{~mm}$. The roots were placed in aluminum molds (16 x $16 \times 32 \mathrm{~mm})$ and embedded in acrylic resin (Jet; Clássico, São Paulo, SP, Brazil) to maintain $2 \mathrm{~mm}$ of root length extending beyond the top of the acrylic resin.
The specimens were randomly distributed into 3 groups $(n=20)$, according to the period between obturation and post cementation: GI - immediately, GII - $72 \mathrm{~h}$ and GIII - 4 months. Each group was divided into two subgroups $(n=10)$, according to the luting agent used for fixation of the intraradicular posts: A - Zinc phosphate cement (SS White, Rio de Janeiro, RJ, Brazil) and B - Panavia F dual-cured resin cement (Kuraray Co Ltd, Osaka, Japan).

The cervical and middle thirds were prepared using Largo drills (Dentsply/Maillefer, Ballaigues, Switzerland) sizes 1 (0.70 diameter $\mathrm{mm}), 2(0.90 \mathrm{~mm})$ and $3(1.10$ $\mathrm{mm})$. The root canals were explored with a size $25 \mathrm{~K}$-file (Dentsply/Maillefer) to select specimens with a working length of $13 \mathrm{~mm}$ (1 mm short of the apical foramen) and anatomic diameter of $250 \mu \mathrm{m}$. Instrumentation was performed at the working length with hand files up to a size 45 master apical file. The canals were irrigated with $2 \mathrm{~mL}$ of $1 \%$ sodium hypochlorite during instrumentation followed by a final irrigation with $10 \mathrm{~mL}$ of distilled water. After aspiration of liquid content, the canals were dried with absorbent paper points (Dentsply/Herpo, Petrópolis, RJ, Brazil) and obturated with gutta-percha cones (Dentsply/ Herpol) and an eugenol-based endodontic sealer (EndofillÒ; Dentsply Indústria e Comércio Ltda., Petrópolis, RJ, Brazil) using the lateral condensation technique. Extracoronal excess of gutta-percha was removed using heated instruments. Vertical condensation was done with the same instruments and the pulp chamber was sealed with a noneugenol, self-setting, single-component temporary coronal filling material (Coltosol ${ }^{\circledR}$; Coltene-Whaledent, Cuyahoga Falls, OH, USA). Specimens were stored in distilled water at $37 \pm 2{ }^{\circ} \mathrm{C}$ for $72 \mathrm{~h}$, except for GI's specimens.

In GI, the preparation of the canals was done immediately after obturation, while in GII and GIII the canals were prepared after $72 \mathrm{~h}$ and 4 months, respectively. Post spaces were prepared to a length of $8 \mathrm{~mm}$ with a size 4 Largo drill (Figure 1) mounted at a low-speed handpiece (Dabi Atlante; Ribeirão Preto, SP, Brazil) coupled to a surveyor (Bioart, São Carlos, SP, Brazil). In all groups, cylindrical stainless steel prefabricated posts measuring $1.5 \mathrm{~mm}$ in diameter and $11 \mathrm{~mm}$ in length (Reforpost II \#4; Ângelus, Londrina, PR, Brazil) were used.

In the specimens of GIA, GIIA and GIIIA, the posts were cemented with the zinc phosphate cement prepared with at a ratio of $2.0 \mathrm{~g}$ of powder and $0.5 \mathrm{~mL}$ of liquid. The posts were coated with cement, inserted into the post space and constant finger pressure was applied for $60 \mathrm{~s}$. After $10 \mathrm{~min}$, cement excess was removed with an explorer. In the specimens of GIB, GIIB and GIIIB, the posts were cemented with Panavia F. First, the primer (Alloy Primer; Kuraray Co Ltd.) was applied to the post. Then, each canal surface was acid etched (Ivoclar/Vivadent; São Paulo, SP, Brazil) for $30 \mathrm{~s}$, rinsed and dried with paper points (Dentsply/Herpo). Two coats of the adhesive system (Kuraray Co Ltd.) were applied, air dried for $20 \mathrm{~s}$ and photoactivated for $30 \mathrm{~s}$ with a halogen light source (Ultralux Electronic; Dabi Atlante, Ribeirão Preto, SP, Brazil) with a wavelength of 350 to 500 


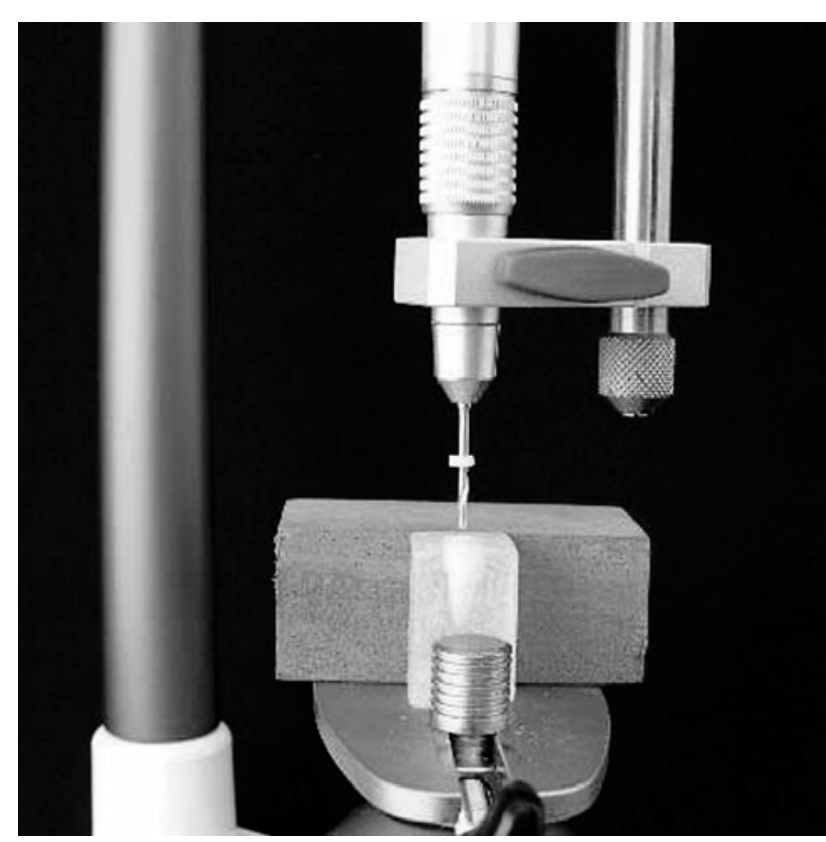

FIGURE 1- Low-speed handpiece coupled to a surveyor for post space preparation

$\mathrm{nm}$ and a light intensity of 350 to $500 \mathrm{mv} / \mathrm{cm}^{2}$. The light guide tip was positioned perpendicular to the root long axis at a distance of $2.0 \mathrm{~mm}$ from the specimen surface. The cement (Panavia F; Kuraray Co Ltd) was applied according to the manufacturer's instructions. A Lentulo spiral instrument (Lentulo; Dentsply/Maillefer) was used for the application of the cement inside the prepared canals, and, to avoid any difficulty resulting from premature polymerization of the resin cement in the canal, the post was inserted immediately after cement placement. Any excess cement was removed, and the core was maintained under constant finger pressure for $60 \mathrm{~s}$. The halogen light (Ultralux Eletronic; Dabi Atlante) was activated for $60 \mathrm{~s}$, in the same way as described for photoactivation of the adhesive layer. A waiting period of 6 min was used to allow complete polymerization of the cement. An oxygen barrier (Oxyguard II gel; Kuraray Co Ltd) was applied to the superficial margins for $10 \mathrm{~min}$ and then removed with cotton rolls and water spray.

After storage at $37 \pm 2{ }^{\circ} \mathrm{C}$ for 72 , the specimens were subjected to the pull-out test. Each specimen was fixed to a custom device to be a held in a vertical position to minimize the incidence of non-axial forces, so that traction forces could

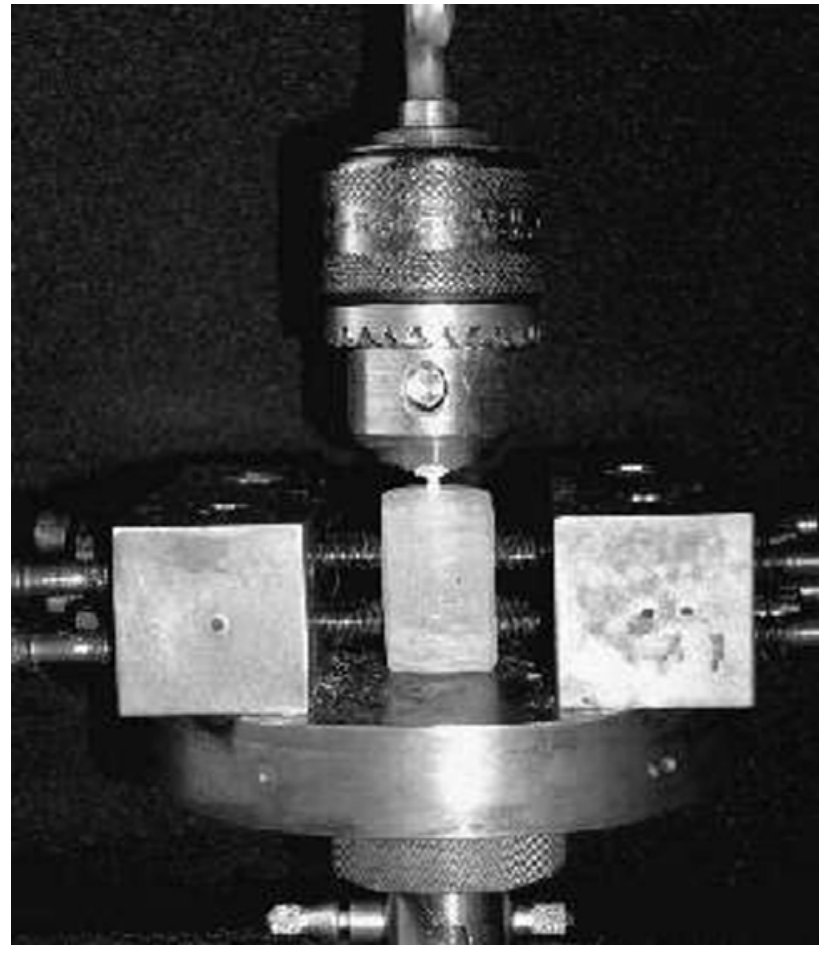

FIGURE 2- Specimen positioned in the universal testing machine

be applied parallel to their long axis. The core of the post was grasped by the mandrill apparatus in a universal testing Machine (Instron 4444; Instron Corporation, Canton, MA, USA) and the force was applied on the post at a crosshead speed of $0.5 \mathrm{~mm} / \mathrm{min}$ until the post was dislodged from the root (Figure 2). Since normal distribution of data was observed, the tensile force values $(\mathrm{kN})$ required for post dislodgment were analyzed statistically by 2 -way ANOVA and Tukey-Kramer test with $\alpha=0.001$.

\section{RESULTS}

The tensile force values $(\mathrm{kN})$ required for post dislodgment after different periods between root canal obturation and post space preparation/post cementation with the two cements are presented in Table 1.

Regarding the luting agent, there was no statistically significant difference between the posts fixed with zinc phosphate cement and those fixed with Panavia F ( $p>0.05)$.

TABLE 1- Tensile force values $(\mathrm{kN})$ required for post dislodgment after different periods between root canal obturation and post cementation with the two cements

\begin{tabular}{|c|c|c|c|c|c|}
\hline \multicolumn{3}{|c|}{ Zinc Phosphate cement } & \multicolumn{3}{|c|}{ Panavia F } \\
\hline Immediate & $72 \mathrm{~h}$ & 4 months & Immediate & $72 \mathrm{~h}$ & 4 months \\
\hline $0.23 \pm 0.04^{\mathrm{a}}$ & $0.20 \pm 0.06^{a}$ & $0.20 \pm 0.06^{a}$ & $0.07 \pm 0.03^{b}$ & $0.04 \pm 0.02^{b}$ & $0.04 \pm 0.01^{b}$ \\
\hline
\end{tabular}

Values are expressed as mean \pm standard deviation. Groups with same superscript letter were not significantly different (Tukey's test; $p>0.05$ ). 
For the interaction cement $\mathrm{x}$ cementation period, there was statistically significant difference $(p<0.001)$ between the posts fixed with zinc phosphate cement immediately, $72 \mathrm{~h}$ and 4 months after obturation compared to the posts fixed with Panavia $\mathrm{F}$ after the same periods.

\section{DISCUSSION}

The loss of retention of an intraradicular post is a frequent failure in dental rehabilitation and is an important factor that influences the success of the treatment. The major factors affecting post retention are: post dimensions (length, diameter), shape (conical, cylindrical) and type of surface (serrated, threaded and smooth); intracanal space preparation; and type of cement used for post fixation ${ }^{6,10,19,18,24,27}$.

In the present study, higher mean tensile force values were needed for vertical dislodgment of the intraradicular posts fixed with zinc phosphate cement compared to those fixed with Panavia F. These results indicate that the eugenolcontaining sealer used for root canal obturation (Endofill) might have altered the polymerization of the resin cement but did not influence the properties of the zinc phosphate cement, which produced higher retention values. Accordingly, Dilts, et al. ${ }^{11}$ (1986) observed that the zinc phosphate cement was the least altered luting agent by the eugenol present in endodontic sealers. Schwartz, et al. ${ }^{22}$ (1998) who found higher retention for prefabricated posts fixed with zinc phosphate cement compared to Panavia 21 resin cement, and Alfredo, et al. ${ }^{2}$ (2006) reported that zinc phosphate cement produced greater retention than Enforce resin cement.

The greater resistance to traction of the posts fixed with zinc phosphate cement may be explained by the physical characteristics of this cement. According to Anusavice ${ }^{4}$ (2005), the adherence with zinc phosphate cement does not involve any reaction with the surrounding mineralized tissue or other restoration materials. Its adhesion is mainly due to mechanical interlocking at the interfaces rather than to chemical interactions. Addition, it has been demonstrated that zinc phosphate cement application technique can also influence post retention, and thus post surface and root canal walls should be coated by a uniform cement layer ${ }^{26}$.

There are divergent opinions from authors who have investigated the possible influence of the eugenol contained in some endodontic sealers on the polymerization of resin cements used for fixation of intraradicular posts. According to some authors ${ }^{11,13,23,25}$, eugenol has harmful effects on resin compounds since its phenolic components influence the polymerization and thus adversely affects their adhesive properties. The phenolic components are free radical collectors and delay the polymerization reaction when interact with resin materials. Carvalho, et al. ${ }^{8}$ (2007) observed that temporary sealing cement containing eugenol reduced the bonding strength of adhesive systems. On the other hand, Hagge, et al. ${ }^{14}$ (2002) concluded that the chemical formulation of endodontic sealers did not affect significantly the retention of posts cemented with resin cements. Schwartz, et al. ${ }^{22}$ (1998) observed that the type of endodontic sealer used (with or without eugenol) did not affect the retention of resin cement used for the fixation of intraradicular posts. Other authors have also affirmed that eugenol had no deleterious effect on resin cements ${ }^{1,3,10}$.

The results obtained in this study in relation to the different preparation and post cementation times (immediately, $72 \mathrm{~h}$ and 4 months after obturation) did not show a significant difference $(\mathrm{p}>0.05)$ between the groups, regardless of the cement used for post fixation. Although mean tensile force values needed for dislodgment of the posts fixed with Panavia F were lower than those fixed with zinc phosphate cement, the different time periods between root canal obturation and post cementation in this group did not lead to different results. The group where post preparation and cementation were done immediately after obturation showed a slightly higher value $(0.07 \mathrm{kN})$ than those in which these procedures occurred after $72 \mathrm{~h}$ and 4 months $(0.04 \mathrm{kN}$ and $0.04 \mathrm{kN}$, respectively).

The fact that the retention of the posts fixed with resin cement did not change with the different time periods, may be explained by the fact that the diffusion of eugenol through dentin occurs rapidly within the first $24 \mathrm{~h}$, decreasing slowly and reaching a concentration of $10^{-2} \mathrm{~mol} / \mathrm{L}$ in the zone immediately adjacent to the material, where it remains constant for more than 1 week $^{12,15}$. The occurrence of this phenomenon has been supported by some studies ${ }^{6,7,25}$ that stated that irrigating solutions, acid etching and post space preparation may demineralize and remove part of dentin surface, which would be sufficient for eliminating cement excess from the dentinal tubules. According to those authors ${ }^{6,7,25}$, these mechanical and chemical processes may limit the amount of free eugenol, reducing its interference in resin cement polymerization, regardless of the contact time of the cement with the dentin surface. Nevertheless, Hagge, et al. ${ }^{13}$ (2002) found that the longer the obturation time of the root canal with zinc oxide and eugenol-based cement, the greater the negative influence on the retention of intraradicular posts, probably due to the greater penetration of eugenol in the dental tubules.

In this way, some questions related to the behavior of resin compounds when in contact with eugenol-based materials remain unclear, mainly with respect to the time interval between canal obturation and its preparation to receive an intraradicular post. Further research is needed since these materials are widely used and the time elapsed between endodontic and prosthetic procedures varies considerably in clinical practice, possibly leading to implications that may culminate in unsuccessful treatment.

\section{CONCLUSIONS}

Based on the methodology used and the obtained results, it may be concluded that: 1 . Regarding the cementing agent, the posts fixed with zinc phosphate cement showed higher retention values than those fixed with resin cement; 2 . 
Regarding the different periods between obturation and post space preparation/post cementation (immediately, $72 \mathrm{~h}$ and 4 months), there was no significant difference between the groups, regardless of the cementing agent used.

\section{REFERENCES}

1- Abo-Hamar SE, Federlin M, Hiller KA, Friedl KH, Schmalz G. Effect of temporary cements on the bond strength of ceramic luted to dentin. Dent Mater. 2005;21(9):794-803

2- Alfredo E, Souza ES, Marchesan MA, Paulino SM, Gariba-Silva R, Sousa-Neto MD. Effect of eugenol-basead endodontic cement on the adhesion of intraradicular posts. Braz Dent J. 2006;17(2):130-3

3- Alves FBT, Vieira RS. Effects of eugenol and non-eugenol endodontic fillers on short post retention, in primary anterior teeth: an in vitro study. J Clin Pediatr Dent. 2004;29(3):211-4.

4- Anusavice KJ. Phillips'Science of dental materials. 11th ed. Philadelphia: WB Saunders; 2003.

5- Bachicha WS, Difiore PM, Miller DA, Lautenschlager EP, Pashley $\mathrm{DH}$. Microleakage of endodontically treated teeth restored with posts. J Endod.1998;24(11):703-8.

6- Boone KJ, Murchison DF, Schindler WG, Walker III WA. Post retention the effect of sequence of post-space preparation, cementation time, and different sealers. J Endod. 2001;27(12):768-71.

7- Burns DR, Moon PC, Neal PW, Burns DA. Effect of endodontic sealers on dowels luted with resin cement. J Prosthodont. 2000;9(3):137-41.

8- Carvalho CN, Oliveira B Jr, Loguercio AD, Reis A. Effect of ZOE temporary restoration on resin-dentin bond strength using different adhesive strategies. J Esthet Restor Dent. 2007;9(3):144-52.

9- Cohen BI, Pagnillo MK, Newman I, Musikant BL, Deutsch AS Retention of three endodontic posts cemented with five dental cements. J Prosthet Dent. 1998;79(5):520-5.

10- Davis ST, O' Connell BC. The effect of two root canal sealers on the retentive strenght of glass fibre endodontic posts. J Oral Rehabil. 2007;34(6):468-73.

11- Dilts WE, Miller RC, Miranda FJ, Duncanson MG Jr. Effect of zinc oxide-eugenol on shear bond strengths of selected core/cement combinations. J Prosthet Dent. 1986;55(2):206-8.

12- Gomes AL, Gomes OS, Sampaio-Fernandes JC, Leal C, Pinho A. Materiais de resina e superfícies contaminadas com eugenol. Rev Port Estomatol Cir Maxilofac. 2006;47(2):107-15.

13- Hagge MS, Wong RDM, Lindemuth JS. Effect of three root canal sealers on the retentive strength of endodontic posts luted with a resin cement. Int Endod J. 2002;35(4):372-8.

14- Hagge MS, Wong RDM, Lindemuth JS. Retention of posts luted with phosphate monomer-based composite cement in canals obturated using a eugenol sealer. Am J Dent. 2002;15(6):378-82.

15- Hume WR. In vitro studies on the local pharmacodynamics, pharmacology and toxicology of eugenol and zinc oxide-eugenol. Int Endod J. 1988;21(2):130-4

16- Iglesia-Puig MA, Arellano-Cabornero A. Fiber-reinforced post and core adapted to a previous metal ceramic crown. J Prosthet Dent. 2004;91(2):191-4
17- Love RM, Purton DG. Retention of posts with resin, glass ionomer and hybrid cements. J Dent. 1998;26(7):599-602.

18- Mitchell CA. Selection of materials for post cementation. Dent Update. 2000;27(7):350-4

19- Ng CC, Dumbrigue HB, Al-Bayat MI, Griggs JA, Wakefield CW. Influence of remaining coronal tooth structure location on the fracture resistance of restored endodontically treated anterior teeth. J Prosthet Dent. 2006;95(4):290-6

20- Saade CJO. Efecto de los compuestos eugenólicos en los materiales utilizados en endodoncia sobre la unión de los sistemas adhesivos [Internet]. Venezuela: Universidad Central de Venezuela; 2003. 42 p. Available from: www.odont.ucv.ve/coordinacion_investigacion/Tesis.

21- Saupe WA, Gluskin AH, Radke RA Jr. A comparative study of fracture resistance between morphologic dowel and cores and resin-reinforced dowel system in the intraradicular restoration of structurally compromised roots. Quintessence Int. 1996;27(7):483-91.

22- Schwartz RS, Murchison DF, Walker III WA. Effects of eugenol and noneugenol endodontic sealer cements on post retention. J Endod. 1998;24(8):564-7.

23- Souza AR, Mello FB, Turbino ML, Youssef MN. Influência do eugenol na microdureza da resina composta utilizando sistemas adesivos atuais. Pesqui Odontol Bras. 2000;14(3):237-42.

24- Teixeira CS, Pasternak-Junior B, Borges AH, Paulino SM, SousaNeto, MD. Influence of endodontic sealers on the bond strength of carbon fiber posts. J Biomed Mater R Appl Biomed. 2008;84(2):430-5.

25- Tjan AHL, Nemetz H. Effect of eugenol-containing endodontic sealer on retention of prefabricated posts luted with an adhesive composite resin cement. Quintessence Int. 1992;23(12):839-44.

26- Tuner CH. The retention of dental posts. J Dent. 1982;10(2):154-65.

27- Vano M, Cury AH, Goracci C, Chieffi N, Gabriele M, Tay FR, et al. The effect of immediate versus delayed cementation on the retention of different types of fiber post in canals obturated using a eugenol sealer. $\mathbf{J}$ Endod. 2006;32(9):882-5

28- Wu MK, Pehlivan Y, Kontakiotis EG, Wesselink PR. Microleakage along apical root fillings and cemented posts. J Prosthet Dent. 1998;79(3):264-9. 